\title{
Exposure in emergency general surgery in a time-based residency program: A call for review
}

\begin{abstract}
K. Ojuka, MBChB, MMed (Surg), Kapenguria District Hospital, Kenya and H. Saidi, BSc (Anat), MBChB, MMed (Surg), FCS (ECSA), School of Medicine, University of Nairobi, P.O. Box 30197-00100, Nairobi, Kenya
\end{abstract}

Correspondence and reprint requests to:

Dr. H. Saidi, Department of Human Anatomy, School of Medicine, University of Nairobi, P.O. Box 3019700100, Nairobi, Kenya, Email: hsaidi@uonbi.ac.ke

\section{Abstract}

OBJECTIVE: This paper aimed to characterize the resident exposure to acute general surgical conditions during a three-months rotation in a general surgical unit.

SETTING: The Department of Surgery, University of Nairobi and Kenyatta National Referral and Teaching Hospital in Nairobi.

METHODS: Four residents (in their first to third post-basic science year) were evaluated during a 12-week General Surgery rotation. Details assessed included number and variety of admission diagnoses logged by each resident, number and nature of surgical operations performed independently by each resident and with consultant support, and the resident involvement in the continuity of care. The experiences were compared across the residents.

RESULTS: One hundred and forty five patients were admitted. The number of admissions per resident varied between 30 and 41. Fifty-eight patients had surgery. Operative experience where the resident was the principal surgeon ranged from 11 cases to 23 cases per resident. A second resident assisted in 8 out of the fiftyeight cases operated on and consultant support was infrequent.

CONCLUSION: The operative experience was variable for the general surgical residents. Exposure could be improved by a policy of resident assistance at emergency surgery. The infrequent consultant support may invalidate formative assessment of resident competence.

\section{Introduction}

Surgical training world wide is based on apprenticeship. This requires contact with both the patients as well as the trainer. Surgical trainees vary in experience, from recently qualified doctors to those about to exit the program as qualified surgeons. During this period they assist in operations, perform operations under supervision, and then perform operations without direct supervision, progressing from routine to more complex procedures. It is essential that all trainees can carry out the prescribed operations in the general surgery curriculum without supervision by the time their training is complete (1). The surgical training requires acquisition of both knowledge and skill. This acquisition is possible where there is both the volume and case mix that go hand in hand with appropriate supervision (2).

At the University of Nairobi, the general surgery training model is time-based. During a period of $3 \frac{1}{2} 2$ - 4 years, a resident goes through an initial year of basic sciences then starts his clinical rotations including at least 6 months of general surgery. The number of admissions into the training program has been steadily 
increasing. The effect of this increase on the trainee's experience remains unclear.

This study examined the scope and nature of resident exposure to acute surgical conditions at a general surgical unit.

\section{Materials and methods}

Study setting: A General Surgery unit at the Kenyatta National Hospital. In this unit teaching and surgical service is provided by a team of 6 consultants and one senior registrar. Residents spend three months in this unit during which time they learn to admit, design patients' plan of care and operate on those who need surgery. Clinical rotations commence after an initial year of basic science course. A typical rotation would involve admission twice or thrice every week for a total of 12 weeks divided between the residents. The acute service exposes the resident to acute non-skeletal trauma, general surgery and urological emergencies. On call consultants are available for senior input in this plan of care.

Study design: Retrospective chart review.

Patients and methods: Case records of acute general surgical admissions during a 3-month rotation (September $18^{\text {th }}$ to December $11^{\text {th }}, 2006$ ) for four residents were retrieved and analyzed. The residents were in their first (R1), second (R2), third (R3) and fourth (R4) post basic science years. Data abstracted for each resident included the following: admission diagnosis, involvement in continuity of care, operation as principal surgeon, operation as assistant surgeon, nature of surgical procedure, postsurgical complications, re-operation, mortality, and patient length of hospital stay. The data were entered and analyzed using the SPSS version 12.0 statistical program for means and frequencies. The results are presented in tables and bar charts.

\section{Results}

There were 201 recorded emergency admissions during the clinical rotation. The chart retrieval rate was $145(72 \%)$. Eight files were missing while 48 files had discordant registration details. Most admissions $(51.1 \%)$ were trauma related (Table 1). Common diagnoses included head trauma (42 cases), abscesses and cellulitis (14 cases) and peritonitis (10 cases). The number of admission cases per resident averaged $36 ; 30$ for R1, 37 for R2 and R3 and 41 for R4 (Figure 1).

\section{Table 1: Exposure by admission diagnosis}

\begin{tabular}{lcc} 
Diagnosis & No. & $(\%)$ \\
Head trauma & 42 & 29 \\
Other trauma & 32 & 22.1 \\
Appendicitis & 9 & 6.2 \\
Urine retention & 3 & 2.1 \\
Intestinal obstruction & 9 & 6.2 \\
Hernia & 3 & 2.1 \\
Abscesses/cellulites & 14 & 9.7 \\
Peritonitis & 10 & 6.8 \\
Acute scrotum & 5 & 3.4 \\
Others & 18 & 12.4 \\
\hline
\end{tabular}

The proportion of patients requiring surgery was $58(40 \%)$. The most common $(31 \%)$ emergency procedure was laparatomy (18 cases) followed by incision and drainage (13 cases) and appendicectomy (8 cases) (Figure 2 ). The resident exposure to various surgical procedures was varied (Table 2). R4 was principal surgeon double the exposure for the other residents. Total operative exposures (as a principal surgeon and first assistant) for R1, R2, $\mathrm{R} 3$ and $\mathrm{R} 4$ residents were $15,14,13$ and 24 cases respectively. Incision and drainage was the most frequent operation performed by R1. The $\mathrm{R} 1$ resident performed a single appendicectomy and one laparatomy during the rotation. The R4 resident performed 4 appendicectomies and 10 laparotomies (Table 3). R3 performed the only suprapubic cystostomy and three tube thoracostomies during this rotation. R2 performed one and R4 performed two of the three emergency herniorraphies. 
Figure 2. Exposure by type of surgery performed

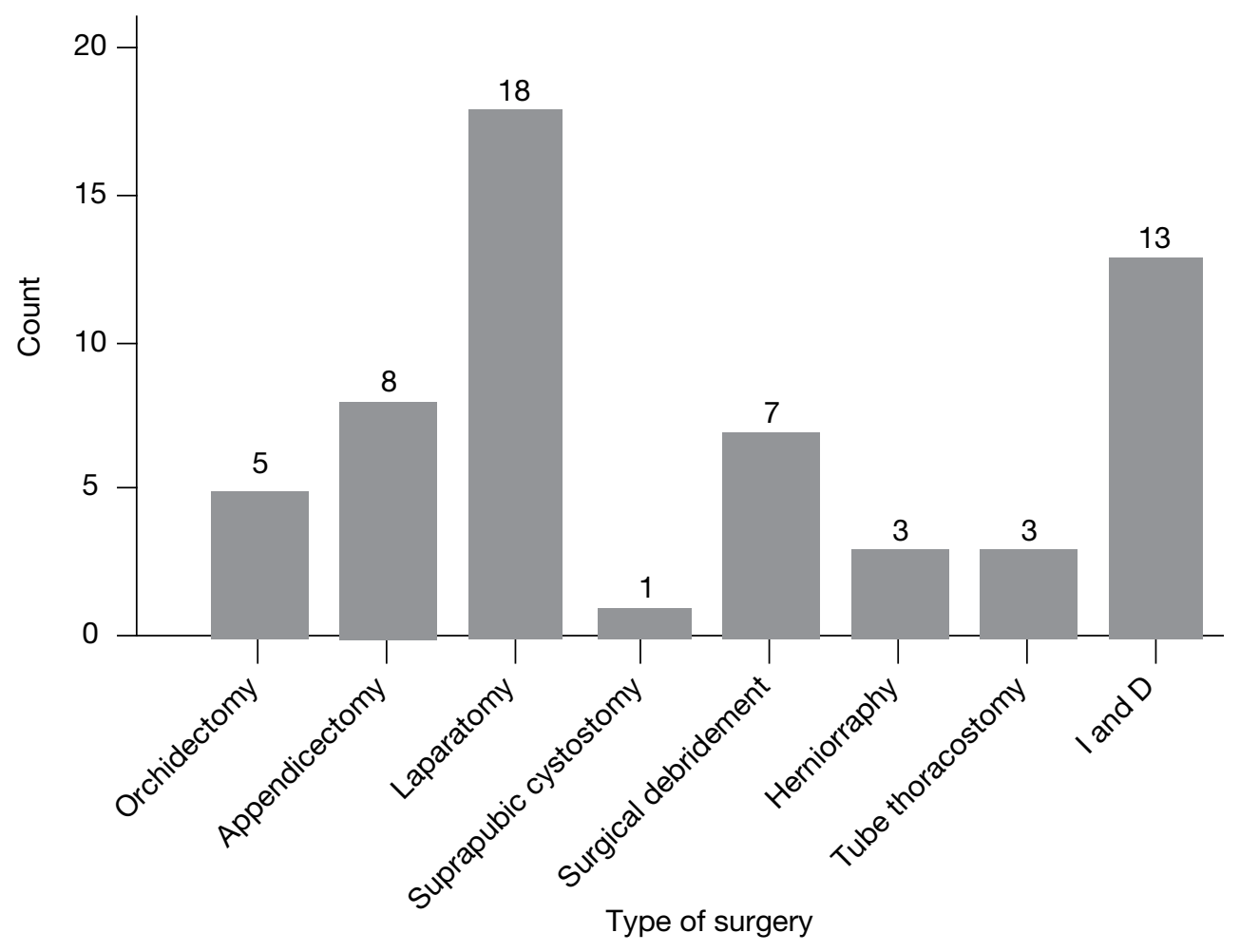

Table 2: Exposure of resident as principal surgeon or first assistant

\begin{tabular}{lccc} 
Principal & $\begin{array}{c}\text { Assistant } \\
\text { surgeon } \\
\text { Number }\end{array}$ & $\begin{array}{c}\text { Total } \\
\text { surgeon } \\
\text { Number }\end{array}$ & \\
\hline R1 & 11 & 4 & 15 \\
R2 & 13 & 1 & 14 \\
R3 & 11 & 2 & 13 \\
R4 & 23 & 1 & 24 \\
\hline
\end{tabular}

There were eight complications (5.5\%). These included infections (5), bleeding (2) and prolonged ileus (1). Three patients died, one of whom died after reoperation. Consultant involvement was sought for this single case needing reoperation. The mean hospital stay was 9.28 days with a range from one to 48 days.

Table 3: Exposure by the type of surgeries performed

\begin{tabular}{lcccc} 
& $\mathrm{R} 1$ & $\mathrm{R} 2$ & $\mathrm{R} 3$ & $\mathrm{R} 4$ \\
Orchiectomy & 0 & 1 & 1 & 3 \\
Appendectomy & 1 & 1 & 2 & 4 \\
Laparotomy & 1 & 5 & 2 & 10 \\
Surgical debridement & 3 & 2 & 0 & 2 \\
Incision and drainage & 6 & 3 & 2 & 2 \\
\hline
\end{tabular}

\section{Discussion}

The results of this study show an appreciable case mix admitted over twelve weeks. Maximal exposure to this case mix was limited by the shared calls. With four rotating residents, the volumes recorded per resident were considerably low. One resident required the whole rotation to perform a single appendicectomy and laparotomy. In a timebased program, the resident would still move to his next rotation without acquisition of skills required for acute general surgery. The current data depict the inherent danger in the program assuming equality of exposure for residents in a particular unit for a particular length of time. The requirement for the program at the current moment indicates a minimum number of 20 appendicectomies and laparotomies a resident should competently undertake during their general surgery rotation (3). It is improbable that the $\mathrm{R} 1$ resident in this study would attain this by the end of his second general surgery rotation. This study also noted a poor level of residents assisting each other (Table 2) during the surgical operations analyzed. A policy of 
residents assisting each other on a mandatory basis may improve resident operative surgery exposure.

The observation that the residents undertook most of the operations independently is a positive aspect of the program. This is good for resident confidence in surgical decision making. The excellent outcome profile recorded arguably serves to demonstrate competence for the operators. But, some level of supervision is required in surgical training, even if to assist or watch over what the residents are performing. In Western literature, trainees are unassisted in two thirds of the time $(7,8)$ with many of their unassisted procedures performed out of hours.

The senior resident seemed to take up more operative responsibilities for work probably left by the juniors. But, competence is best ascertained through direct observation of procedural skills (DOPS) by the concerned instructors (4). Other formative assessment tools include OSATS (objective structured assessment of technical skills) (5) and RITA (record of in-training assessment) (6). The log book is a useful tool in competence evaluation but it is often completed after the event and could be subjective and unreliable (4).

The limited operative surgery exposure could likely be explained by increased number of surgical trainees. Unlike in Europe where exposure time has been influenced by the implementation of Report of the Confidential Enquiry into Perioperative Deaths (9); European Working Time Directive (10) as well as Junior doctor's deal (11), reduced time is not an issue in the training program here. Either way, trainee-trainer interactions as well as time in theatre suffer (12). The answer may seem to be looking at the competence beyond the minimum period (13).

The results in this study also show that most admissions are trauma related and that most often the operations performed were laparotomies. This would reinforce the early familiarity with the advanced trauma life support and acquisition of basic surgical skills including intestinal anastomoses early in the training.

In conclusion, the level of operative exposure is varied but relatively low. Acquisition of skills may be enhanced by a policy of residents assisting each other during operations and exploring the competence beyond the minimum period. The low level of supervision invalidates the formative assessment of resident competence.

\section{References}

1. Charles G. and Collins M. Unsupervised surgical training: logbooks are essential for assessing progress. BMJ. 1997; 315: 1306-1307.

2. Charles C. Surgical training, supervision and service. BMJ. 1999; 318: 682-683.

3. Surgical Registrars' Logbook. Department of Surgery, University of Nairobi 2003 version.

4. Shah J. and Darzi A. Surgical assessment: an on-going debate. BJU Int. 2001; 88: 655-660.

5. Martin J.A., Regehr G., Reznick R., et al. Objective structured assessment of technical skill (OSATS) for surgical residents. Brit. J. Surg 1997; 84(2): 273-278.

6. Ringsted C., Østergaard D. and van der Vleuten M. Implementation of a formal in-training assessment programme in anaesthesiology and preliminary results of acceptability. Acta. Anaesthesiol. Scand. 2003; 47(10): 1196-1203.

7. Cobb R.A., Baigrie R.J., Harris P., et al. What constitutes general surgical training? Evidence from the log books of trainees in one district general hospital. Ann. R. Coll. Surg. Engl. 1994; 76(suppl): 117-120.

8. Potter M.A., Griffiths J.M.T., Aitken R.J. et al. An objective assessment of surgical training. Ann. R. Coll. Surg. Engl. 1996; 78(Suppl): 11-13.

9. Buck N., Devlin H.B. and Lunn I.N. Report of the Confidential Enquiry into Perioperative Deaths. London: Nuffield Provincial Hospitals Trust and the King's Fund Publishing Office, 1987.

10. Lowry J. and Cripps J. Results of online European Working Time Directive survey. Ann. R. Coll. Surg. Engl. 2005; 87(Suppl): 86-87.

11. Junior Doctors. The New Deal. London: Department of Health and Social Security, 1991.

12. McKee M., Priest P., Ginzler M. et al. Which General Surgical operations must be done at night? Ann. R. Coll. Surg. Engl. 1991; 73: 295-302.

13. Aman S. Connar. The rot is deep, a column in Royal College of Surgeons of England response to No time to train surgeons. BMJ. 2004; 328: 1133-1134. 